\title{
MINING SEISMIC THERMAL ANOMALIES FROM MASSIVE SATELLITE PASSIVE MICROWAVE IMAGES
}

\author{
Y. Qi ${ }^{1,2}$, L. X. Wu ${ }^{1,2 *}$, Y. F. Ding ${ }^{1,2}$, M. He ${ }^{1,2}$, W. F. Mao ${ }^{3,2}$, B. S. Xie ${ }^{1,2}$, S. Y. Zhou ${ }^{1,2}$ \\ ${ }^{1}$ School of Geosciences and Info-Physics, Central South University, Changsha, China - (qiyuan_rs, wulx66, dyfzz2020, freyahe, \\ bushengxie,185012113)@csu.edu.cn \\ ${ }^{2}$ Laboratory of Geo-Hazards Perception, Cognition and Predication, Central South University, Changsha, China \\ ${ }^{3}$ School of Resource and Civil Engineering, Northeastern University, Shenyang, China - maowf2014@126.com
}

\section{Commission III, III/2}

KEY WORDS: Passive Microwave Images, Microwave Brightness Temperature, STW-TSM, Thermal Anomaly, Earthquake, Positive holes

\begin{abstract}
:
Satellite passive microwave radiative signals are considered to reflect thermal radiation and energy exchange of the Earth's surface, and the microwave brightness temperature (MBT) has been preliminary adopted for pre-earthquake thermal anomaly monitoring in recent decades. Based on the spatio-temporally weighted two-step method (STW-TSM), this paper aims to uncover the evolution characteristics of MBT anomaly prior to typical earthquakes (EQs), i.e. the Mw7.9 Wenchuan EQ in May 2008, the Nepal EQs in April and May 2015, and the Mw5.8 Yibin EQ in June 2019, and to explore and recognize their differences and commonalities. The results are summarized as: 1) significant MBT positive anomalies appeared east and southwest close to the epicenter before the Wenchuan $\mathrm{EQ}$, and the east anomaly migrated northeastward along Longmenshan faults with aftershocks, then the two anomalies dissipated subsequently with the ceasing of large aftershocks $(\mathrm{Mw}>5.5)$. 2) the MBT positive anomalies of Nepal EQs firstly appeared along the Himalayas and became most obvious 1 day before the main shock, and dissipated subsequently after the first shock, and that of the second shock behaved in the same spatiotemporal patten. 3) regional positive MBT anomalies appeared around the epicenter a half month before the Yibin EQ and diminished over time, and the most obvious abnormal area transferred from the central and northwest to the southwest study area. It exhibited that MBT positive anomalies prefer to appear at the mechanically relaxed zones, such as the loose Quaternary with Wenchuan EQ, the cliff peaks with Nepal EQs, and the mountains surrounding Yibin EQ's epicenter, which can be attributed to the declining of ground surface microwave dielectric caused by stress activated P-holes during the period of seismogenic preparation. This research provides a novel insight into mining MBT anomalies associate with large earthquakes and a possibility to explore the potential mechanism of such abnormal phenomena.
\end{abstract}

\section{INTRODUCTION}

Earthquake (EQ) is one of the most destructive natural hazards, and the remote sensing study on monitoring abnormal preearthquake signals has been conducted for many decades (Gornyi et.al., 1988; Tronin, 1996; Qiang et.al., 1997; Saraf and Choudhury, 2004; Tramutoli et al., 2005; Wu et.al., 2012, 2016; Qin et.al., 2013). It is considered that the microwave radiative signals can reflect the thermal radiation and energy exchange of the superficial planet Earth owing to its capability in penetrating the ground surface at different depth. In the last twelve years, satellite passive microwave remote sensing was becoming an indispensable aspect in detecting seismic-related signals for its effective observations on the Earth surface and capability of indicating potential precursors, and its application has achieved some remarkable results and greatly promoted the remote sensing research on earthquake monitoring as well as forecasting (Maeda and Takano, 2008, 2010; Takano and Maeda, 2009; Singh et.al., 2010; Chen and Jin, 2011; Jing et. al., 2018; Qi et.al., 2020).

The emission and transmission of microwave radiation signals are closely related to the physical properties of coversphere (sands, soil, water, ice, snow, forest and vegetation on the Earth's surface) and atmosphere, and strongly influenced by numerous geographical, meteorological and geophysical factors that change with time and space. These diversiform effects in time and space domains should be fully considered when processing and applying microwave images, but the existing researches do not pay enough attention to them.
Meanwhile, due to the inconsistency of methods for information extraction and data usage, there is a great diversity of revealed abnormal phenomena at present, and there exists also a lack of comprehensively study on the generality and personality of MBT anomalies among different seismic cases. Therefore, how to retain and obtain the abnormal signals actually related to EQs by excluding a variety of non-seismic factors and explore the mechanism of the abnormal phenomena through comparative analysis is a very critical problem.

The Mw7.9 Wenchuan earthquake in May 12, 2008, the Mw7.8 and Mw7.3 Nepal earthquakes in April 25 and May 12, 2015, respectively, and the Mw5.8 Yibin earthquake in June 172019 are selected as three typical case studies. And the evolution characteristics of the MBT anomalies prior to the three inland EQs are uncovered based on the spatio-temporally weighted twostep method (STW-TSM) (Qi et al., 2020), with satellite passive microwave data from Aqua AMSR-E, FY-3B MWRI, and GCOM AMSR2 at $10.65 \mathrm{GHz}$, respectively. The differences and commonalities among the results are basically analyzed and recognized in this research, which demonstrate practical application of STW-TSM methods and provides some experiences on mining and recognizing MBT anomalies associate with large EQs.

\section{METHODOLOGY}

It is well known that terrain, vegetation coverage, and seasonal climate in a given area keep usually a relatively stable state and change slightly over years, whose influences on MBT

* Corresponding author 
observations can be considered as long-periodic stable factors. In addition, regional meteorological conditions are capricious in relatively short periods and present spatial heterogeneity with geo-locations, whose disturbance on MBT observations can be considered as short-term variable factors. Therefore, in the presence of tectonic activities and earthquake preparation, satellite observation on the footprint is actually a mixture of these non-seismic contributions and the additional slight increment of seismic microwave signals. The approach of STW-TSM is to obtain the basic and cleaned MBT residuals of ground surface MBT by removing long periodical general trend of MBT observations and restraining short term changeable meteorological noise with two separate data processing steps (Qi et al., 2020), which are described as in the following two parts.

\subsection{The first step}

Referring to the first law of geography (Miller, 2004) and its extension in time domain, the historical non-seismic data are given with varied time-weights according to their annual time intervals with the shocking year, and a temporal weighting background is established by calculating the weighted mean of historical data to remove the general trend of regional MBT, so as to retrieve basic residuals of the shocking year.

$$
\begin{gathered}
T_{w}\left(x, y, t_{\xi}\right)=\frac{\sum_{i=1}^{n}\left[\exp \left(-\frac{\left(\varphi_{i}-\xi\right)^{2}}{D_{1}^{2}}\right) \cdot T\left(x, y, t_{i}\right)\right]}{\sum_{i=1}^{n} \exp \left[-\frac{\left(\varphi_{i}-\xi\right)^{2}}{D_{1}^{2}}\right]} \\
\Delta T\left(x, y, t_{\xi}\right)=T\left(x, y, t_{\xi}\right)-T_{w}\left(x, y, t_{\xi}\right)
\end{gathered}
$$

where $\psi_{i}$ represents any non-earthquake year with a serial number $i, D_{1}$ refers to the maximal year-interval between shocking year and all non-earthquake years. $T\left(x, y, t_{i}\right)$ and $T\left(x, y, t_{\xi}\right)$ stand for the observation values of pixel $(x, y)$ on the date of $t_{i}$ and $t_{\xi}$, respectively. $T_{w}\left(x, y, t_{\xi}\right)$ is the weighted reference value for the earthquake year calculated from all $T\left(x, y, t_{i}\right), \Delta T\left(x, y, t_{\xi}\right)$ means the basic residual value of pixel $(x, y)$ on the date $t_{\xi}$.

\subsection{The second step}

Based on the general-trend-removed basic MBT residuals, the adjacent pixels inside the seismic preparation zone are endowed with different space-weights referring to their Euclidean distances away from the upcoming epicenter, and a spatial weighting reference is obtained to represent the regional meteorological noise, and to be removed so as to obtain the cleaned MBT residuals.

$$
\begin{gathered}
T_{m}\left(x, y, t_{\xi}\right)=\frac{\sum_{k=1}^{p}\left[\exp \left(-\frac{\left(i_{k}-x\right)^{2}+\left(j_{k}-y\right)^{2}}{D_{2}^{2}}\right) \Delta T\left(i_{k}, j_{k}, t_{\xi}\right)\right]}{\sum_{k=1}^{p}\left[\exp \left(-\frac{\left(i_{k}-x\right)^{2}+\left(j_{k}-y\right)^{2}}{D_{2}^{2}}\right)\right]} \\
\Delta \Delta T\left(x, y, t_{\xi}\right)=\Delta T\left(x, y, t_{\xi}\right)-T_{m}\left(x, y, t_{\xi}\right)
\end{gathered}
$$

where $D_{2}$ is the diagonal length of the study area, $W_{k}$ refers to the spatial weight of pixel $\left(i_{k}, j_{k}\right) . T_{m}\left(x, y, t_{\xi}\right)$ stands for the interpolated value of far-field meteorological impact on pixel $(x$, $y)$ in the shocking day $t_{\xi}$, while $\Delta T\left(i_{k}, j_{k}, t_{\xi}\right)$ represents the value of periphery pixel $\left(i_{k}, j_{k}\right)$ from the differential results of the $1^{\text {st }}$ step. $\Delta \Delta T\left(x, y, t_{\xi}\right)$ is the cleaned residual value of pixel $(x, y)$ in day $t_{\xi}$.

\section{DATA AND PRE-PROCESSING}

\subsection{Satellite MBT data}

The application of STW-TSM are demonstrated with satellite passive microwave data from Aqua AMSR-E, FY-3B MWRI, and GCOM AMSR2 with $10.65 \mathrm{GHz}$ at $\mathrm{H}$ polarization, respectively, for the relatively better performance in uncovering seismic MBT anomalies at this band (Qi et al., 2020).

The AMSR-E was one of the high-performing instruments for Aqua's mission developed by the National Space Development Agency of Japan in 2002 (Kawanishi et al. 2003), which has six bands at $6.9-89 \mathrm{GHz}$ (dual polarization, $\mathrm{V}$ and $\mathrm{H}$ ) with spatial resolution at the ground surface varying from approximately 50 $\mathrm{km}$ at $6.9 \mathrm{GHz}$ to $5 \mathrm{~km}$ at $89 \mathrm{GHz}$. The AMSR2 instrument succeed most of the characteristics of AMSR-E, which expands the AMSR-E observations with multiple bands and constructs the long-term data accumulation. The AMSR-E observed the Earth from June 1, 2002 to October 4, 2011 and was succeeded by AMSR2 from July 2, 2012 (on going). The major comparative performances of the two instruments are described as Table 1.

\begin{tabular}{|c|c|c|c|}
\hline $\begin{array}{c}\text { Center } \\
\text { Freq. } \\
(\mathrm{GHz})\end{array}$ & $\begin{array}{c}\text { Ground IFOV } \\
\text { scan } \times \text { along track }(\mathrm{km}) \\
\text { AMSR-E/AMSR2 }\end{array}$ & $\begin{array}{c}\text { Band } \\
\text { width } \\
(\mathrm{MHz})\end{array}$ & $\begin{array}{c}\text { NE } \Delta \mathrm{T} \\
(\mathrm{K})\end{array}$ \\
\hline 6.925 & $43 \times 75 / 35 \times 62$ & 350 & 0.34 \\
10.65 & $29 \times 51 / 24 \times 42$ & 100 & 0.7 \\
18.7 & $16 \times 27 / 14 \times 22$ & 200 & 0.7 \\
23.8 & $18 \times 32 / 15 \times 26$ & 400 & 0.6 \\
36.5 & $8 \times 14 / 7 \times 12$ & 1000 & 0.7 \\
89.0 & $4 \times 7 / 3 \times 5$ & 3000 & 1.2 \\
\hline
\end{tabular}

Table 1. AMSR-E and AMSR2 characteristics and performance

The FY-3B MWRI is onboard the second-generation Chinese polar-orbiting afternoon-configured meteorological satellite, which measures the earth radiation at frequencies of $10.65,18.7$, 23.8, 36.5, and $89.0 \mathrm{GHz}$ with dual polarization modes (V and H). The FY-3B MWRI observed the Earth from November 5, 2010 to now, and the main characteristics and performances of FY-3B MWRI are shown in Table 2.

\begin{tabular}{|c|c|c|c|}
\hline $\begin{array}{c}\text { Center } \\
\text { Freq. } \\
(\mathrm{GHz})\end{array}$ & $\begin{array}{c}\text { Ground IFOV } \\
\text { scan } \times \text { along track } \\
(\mathrm{km})\end{array}$ & $\begin{array}{c}\text { Band } \\
\text { width } \\
(\mathrm{MHz})\end{array}$ & $\begin{array}{c}\mathrm{NE} \Delta \mathrm{T} \\
(\mathrm{K})\end{array}$ \\
\hline 10.65 & $51 \times 85$ & 180 & 0.5 \\
18.7 & $30 \times 50$ & 200 & 0.5 \\
23.8 & $27 \times 45$ & 400 & 0.5 \\
36.5 & $18 \times 30$ & 900 & 0.5 \\
89.0 & $9 \times 15$ & 2300 & 0.8 \\
\hline
\end{tabular}

Table 2. FY-3B MWRI characteristics and performance

The analyzed passive microwave images in this research cover 9 , 9, and 7 years for the Wenchuan, Nepal and Yibin earthquakes, from AMSR-E, AMSR2 and FY-3B MWRI instrument respectively, which contain more than 2000 swathes for respective cases. The magnitudes of the three earthquake cases are Mw7.9 (Wenchuan EQ), Mw 7.8 (Gorkha EQ) and Mw7.3 (Dolakha EQ), and Mw 5.8 (Yibin EQ), so that the study areas are selected respectively as $10^{\circ} \times 10^{\circ}, 10^{\circ} \times 10^{\circ}$, and $6^{\circ} \times 6^{\circ}$, approximately centered with the main shock epicenter, referring 
to the size of earthquake preparation zones according to Dobrovolsky's equation (Dobrovolsky et al., 1979).

\subsection{Data pre-processing}

Owing to the inevitable data gap from periodic orbiting of the satellite instruments, some part of the data covering the study area were occasionally missed, which leads to final retrievals being limited to incomplete region. Therefore, a slide-window preprocessing algorithm (Qi et al., 2020) is applied by using the average MBT 14 days before and 14 days after a certain date to fill in the data missing zones in the study area, considering that there were little changes during this short-term period compared to the general variation trend of stable factors. Meanwhile, the $28 \mathrm{~d}$ sliding window helps to smooth the periodic effects of celestial tidal stress on general background, which may cause additional force on crustal stress as well potential impacts on seismic thermal anomaly in process of earthquake preparation (Ma et al., 2018).

$$
T(x, y, t)=\frac{1}{2 n} \sum_{i=t-n}^{i=t+n} T(x, y, i) \quad(n=14)
$$

where $(x, y)$ is the geolocation of any pixel. $t$ is the date of data-missing to be filled. $n$ represents half the number of adjacent days. $T(x, y, i)$ is the observation data of any adjacent day $i$ at $(x, y) . T(x, y, t)$ is the average MBT of adjacent $28 \mathrm{~d}$ with all valid observation $T(x, y, i)$.

\section{RESULTS}

\subsection{MBT anomaly of Wenchuan earthquake}

The Mw7.9 Wenchuan earthquake is the worst disaster in recent decades of China, which happened in Sichuan Province, China, at 14:28 pm on May 12, 2008 (Beijing Time). The epicenter of Wenchuan EQ located at $31.00^{\circ} \mathrm{N}, 103.32^{\circ} \mathrm{E}$, with a depth of 19.0 $\mathrm{km}$. More than 40 aftershocks of magnitude greater than Mw5.0 appeared in the Longmenshan faults zone from the main shocking day to the end of May.

Figure 1 depicts the uncovered spatiotemporal evolution of positive MBT anomalies 10 days before and after the May 12 Wenchuan main shock. Significant abnormal areas firstly appeared at two areas in the study region from May 2. One is east close to the epicenter between Longmenshan faults and Longquanshan faults, and another is about $300 \mathrm{~km}$ southwest away from the central Longmenshan faults, whose outlines are consistent with two regional particular quaternary sedimentary zones.

The eastern abnormal areas appeared as strip-shaped, and became more and more significant until the main shock on May 12, Then, the east abnormal area migrated northeastward along Longmenshan faults with aftershocks, and the strip-shaped anomalies dissipated subsequently with the ceasing of large aftershocks (Mw > 5.5) by the end of May, 2008.

The northwestern abnormal areas firstly appeared to be blocky on May 5, and gradually become apparent over time. After the main shock, the northwestern anomalies showed a weakening trend but was still evident until May 18. Finally, this blocky anomaly dissipated together with the east one by the end of May.

\subsection{MBT anomaly of Nepal earthquakes}

The Mw7.8 thrust Gorkha EQ happened in central Nepal on 25 April 2015, following by a series of large aftershocks including a Mw7.3 Dolakha EQ on 12 May 2015. This earthquake series occurred at the junction of the Indian plate and the Eurasian-Asia plate, which were considered to be caused by the northeastward subduction and squeezing of the Indian plate to Himalayan tectonic belt, with long-term accumulated stress and energy reaching the shear strength of the thrust faults, finally causing a sudden slip (Zhao et al., 2015).

Figure 2 shows the revealed the spatiotemporal evolution of MBT anomalies associated with Mw7.8 Gorkha EQ and Mw7.3 Dolakha EQ. It is obvious that the central study area firstly kept a state of relatively calm from April 2 to April 22, 2015. The central areas firstly appeared as significant horizontal striped shaped MBT anomalies on April 24, just right one day before the Mw7.8 Gorkha main shock. And the central MBT anomalies behaved along the Himalaya mountains on April 24 and April 25. The significant MBT positive anomalies showed great overlap with the Himalayas, especially with the cliff-shaped mountainous regions of central Himalaya basin.

After the Gorkha EQ, the whole study area became calm again without obvious MBT anomalies. On May 11, one day before the Dolakha EQ on May 12, the central MBT anomalies occurred again overlapping with the Himalaya mountainous areas and dissipated subsequently after the second shock with the disappearance of seismic activity. The evolution characteristics of MBT anomalies relating to the two shocks were uncovered as the same spatiotemporal pattern. In addition, the spatial distribution of the positive MBT anomalies was consistent with the change of ground altitude in Himalaya area, with higher MBT abnormal values corresponding to the ridgeline regions and lower MBT abnormal values corresponding to the slope regions on two sides of Himalayas.

\subsection{MBT anomaly of Yibin earthquake}

Yibin earthquake occurred in the southern edge of the Sichuan basin on June 17, 2019, with a magnitude of Mw 5.8, following by many strong aftershocks until the end of June. The epicenter located at $28.41^{\circ} \mathrm{N}, 104.93^{\circ} \mathrm{E}$ (Changning county) with a depth of $6.0 \mathrm{~km}$ (USGS). No related research has reported the thermal anomaly of this earthquake so far.

Figure 3 shows the uncovered spatiotemporal evolution of MBT anomalies associated with Mw5.8 Yibin earthquake. The MBT abnormal areas occurred around the epicenter about a half months before the main shock, and the MBT positive anomalies were mainly concentrated in the mountainous areas surrounding Sichuan basin, especially where closing to the northwest faults zone and the central faults zone of the study area.

The values of the central MBT positive anomalies alternated between the positive and the slight negative from June 2 to June 16 , and the southwest anomalies become slightly weakened over time until the shocking day (on June 17, data missing). The areas with the most pronounced MBT anomalies shifted to the southwest 3 days before the mainshock. After June 17, the central and northwest MBT anomalies in the study region diminished to normal level, but the south west area still presented slight 


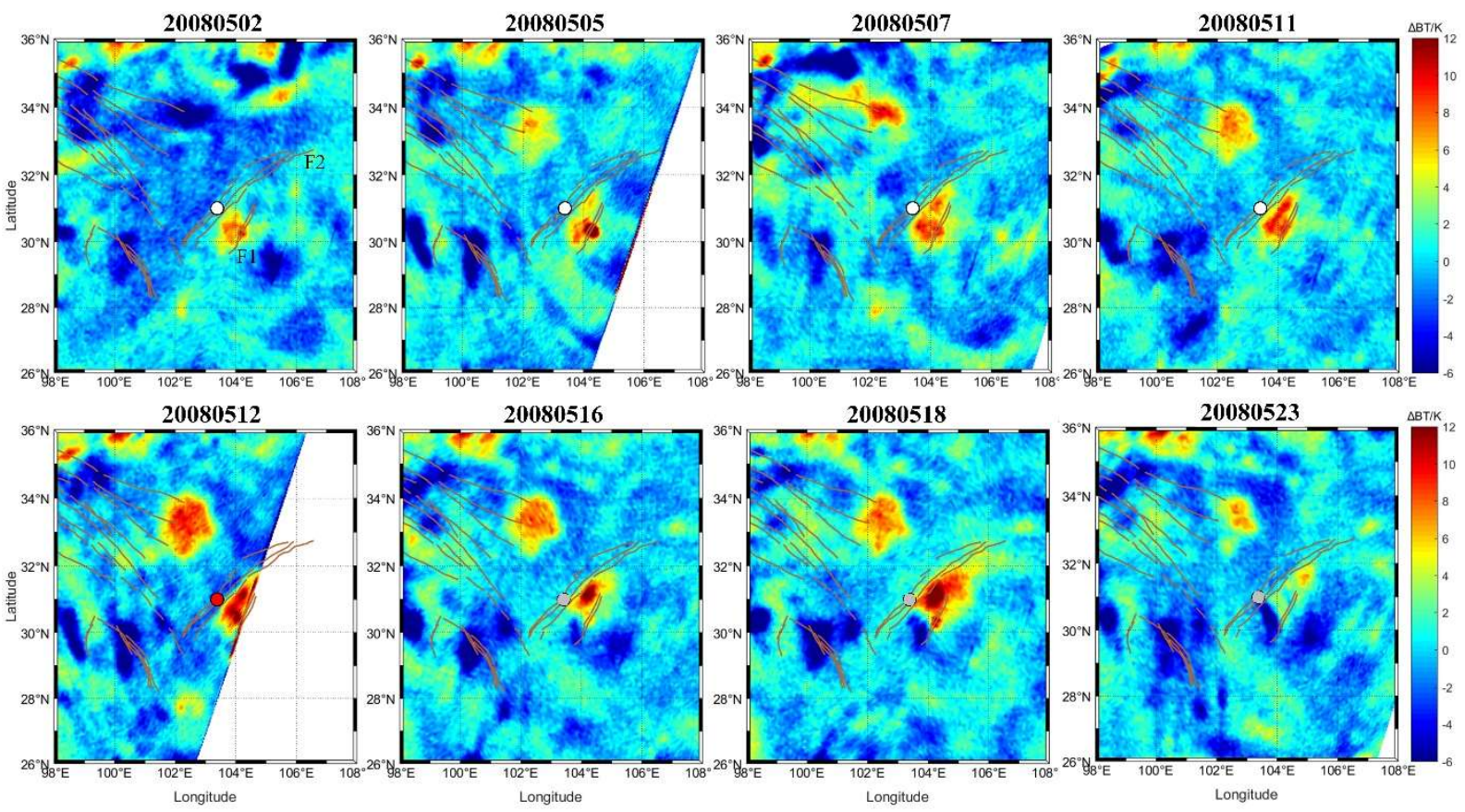

F1: Longmenshan Faults F2: Longquanshan Faults $\quad \sim$ Faults line $\quad$ Epicenter $\quad 10.65 \mathrm{GHz}$ H Polarization

Figure 1. Spatiotemporal evolution of MBT anomalies relating to May 12, 2008 Wenchuan earthquake
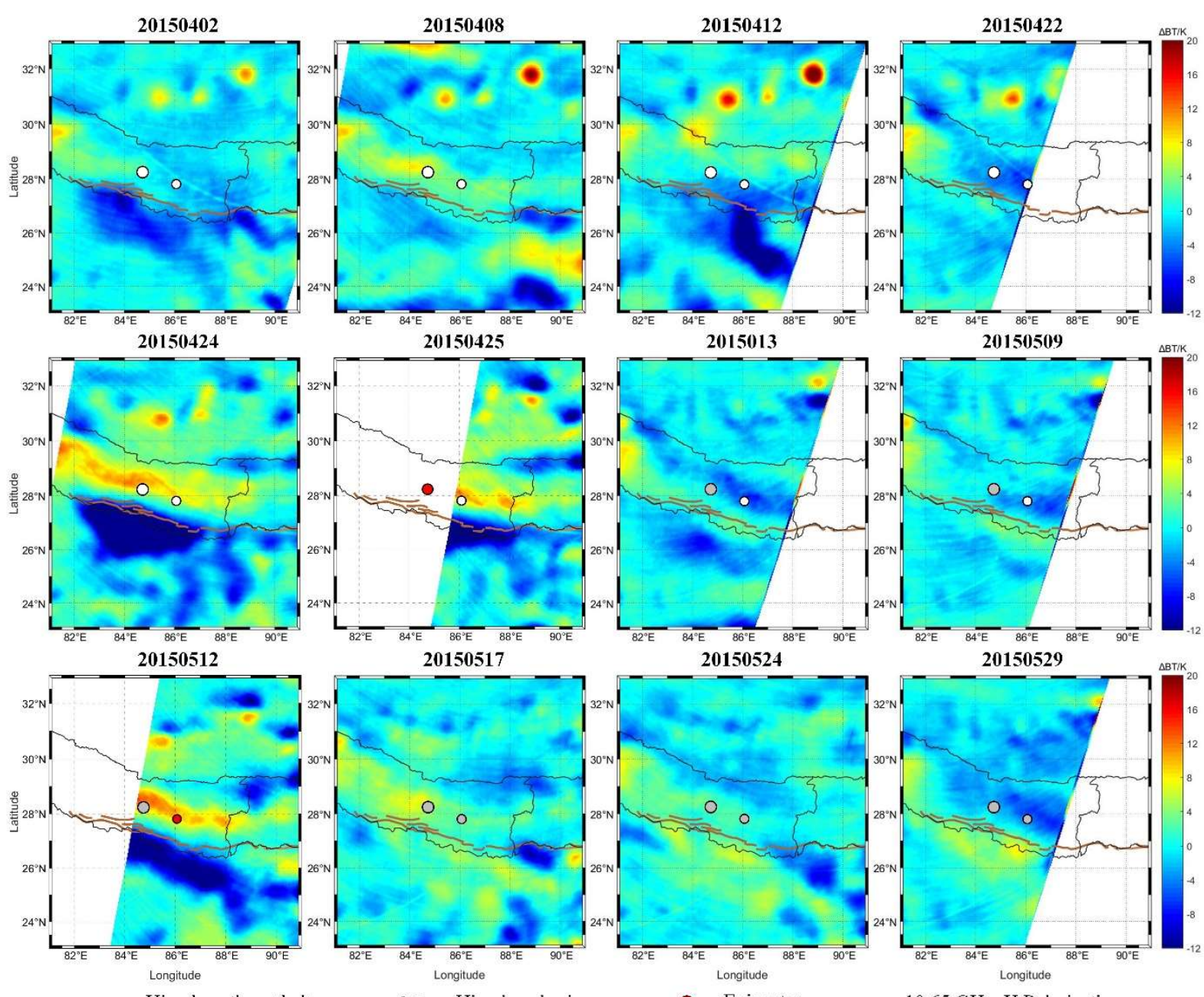

$\sim$ Himalaya thrust belt $\quad \hookrightarrow$ Himalaya basin $\quad \odot$ Epicenter $10.65 \mathrm{GHz}$ H Polarization

Figure 2. Spatiotemporal evolution of MBT anomalies relating to April 25 and May 12 Nepal earthquakes 

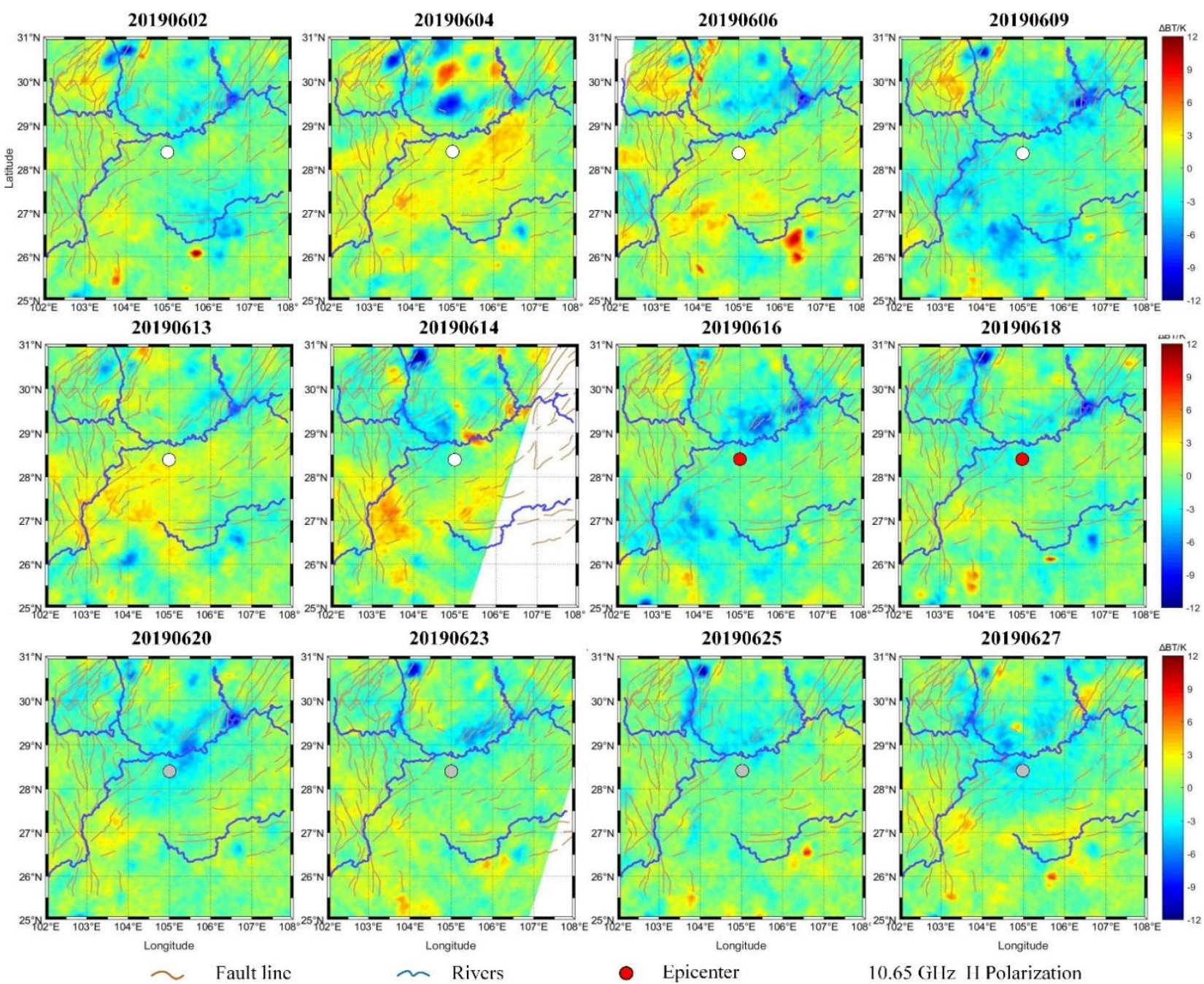

Figure 3. Spatiotemporal evolution of MBT anomalies relating to June 2019 Yibin earthquake
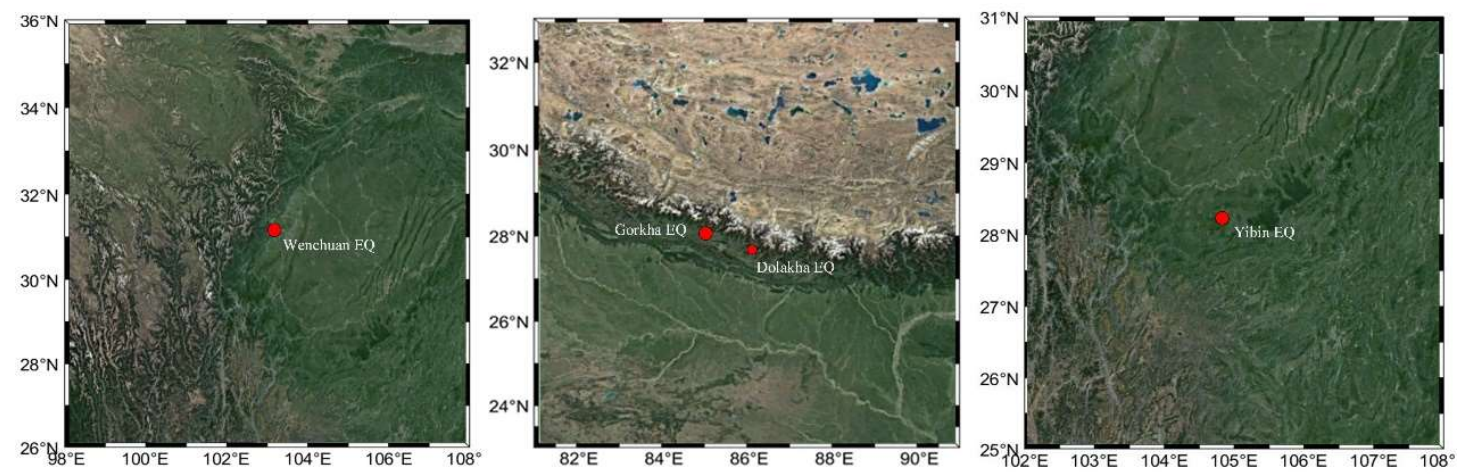

Figure 4. Terrain features in the study areas of the three earthquake cases

abnormal MBT, which may be due to the complex transfer of stress concentration areas for the preparation of aftershocks.

\section{DISCUSSION AND CONCLUSION}

From the results of the three inland earthquake cases, it can be found that the MBT positive anomalies of Wenchuan earthquake appeared at the loose Quaternary area in Sichuan basin east closing to the seismic fault and a relative low area in the northwest, and that of Nepal earthquakes concentrated in the cliff-shaped Himalaya mountainous regions, and that of Yibin earthquake occurred in the surrounding mountainous areas of southwest Sichuan basin (see Fig. 4). Where these anomalies existed are taken for mechanically relaxation zones in consideration of actual geological conditions or crust stress during the process of earthquake preparation. This phenomenon can be considered as a preference of MBT positive anomalies to such specific zones.

During laboratory experiments, Freund et al. (2000, 2009, 2011) discovered that stresses activate mobile electricity charge carriers, also known as positive holes, appeared on stressed rock surface. The positive holes are capable of flowing with stress gradients 
into the distant unstressed rock volume, and accumulating at the rock subsurface of distant end and changing local electric fields at the rock subsurface and even the over covered sand layers (Freund, 2010). The resulting effects of microwave dielectric decrease, fundamental mechanism of MBT increase, are experimentally observed during rock mechanics remote sensing experiments (Mao et.al., 2019, 2020).

Considering that the positive charge carries activated by crust stress alteration in the phase of earthquake preparation might propagate from the deep rock mass upward to the ground surface with relatively lower stress state, and the regional physical properties of ground surface rock or soil get changed and the microwave dielectric constant get decrease, local MBT will get increase and behaved as anomalies.

This research revealed and analyzed the spatiotemporal characteristics of MBT anomalies during the seismogenic processes of three inland earthquakes based on the STW-TSM with massive satellite passive microwave images. The dielectric variation effects in the mechanically relaxed zones caused by accumulated positive holes are identified as a potential mechanism of satellite observed MBT positive anomalies. The discussion about the differences and commonalities of the revealed MBT anomalies provides a novel insight into recognizing the seismic-related abnormal satellite MBT, and the research is fraught with a possibility of earthquake prediction based on the occurrence of enhanced MBT during the last phase of tectonic earthquake preparation.

\section{ACKNOWLEDGEMENTS}

This work is supported by National Key R\&D Program of China (2018YFC15035), the Key Program of the National Natural Science Foundation of China (41930108), the Innovation Leading Program of Central South University (506030101) and the Talents Gathering Program of Hunan Province China (2018RS3013).

\section{REFERENCES}

Chen, H. and Jin, Y. Q., 2011. A preliminary detection of anomalous radiation of rock failures related with Yushu earthquake by using satellite-borne microwave radiometers. Remote Sens. Technol. Appl., 25(6), 860-866.

Dobrovolsky, I. P., Zubkov, S. I., and Miachkin, V. I., 1979. Estimation of the size of earthquake preparation zones. Pure Appl. Geophys., 117, 105-1044.

Freund, F., 2000. Time-resolved study of charge generation and propagation in igneous rocks. J. Geophy. Res., 105(B5), 1100111019.

Freund, F., 2009. Stress-activated positive hole charge carriers in rocks and the generation of pre-earthquake signals. Electromagnetic phenomena associated with earthquakes, 41-96. Freund, F., 2010. Toward a unified solid state theory for preearthquake signals. Acta Geophys., 58(5), 719-766.

Freund, F., 2011. Pre-earthquake signals: Underlying physical processes. J. Asian Earth Sci., 41, 4-5, 383-400.

Gornyi, V. I., Sal'Man, A. G. Tronin, A. A. and Shilin, B. V., 1988. Outgoing infrared radiation of the earth as an indicator of seismic activity. Dokl Akad Nauk SSSR, 301, 67-69.

Jing, F., Singh, R. P., Sun, K., and Shen, X. H., 2018. Passive microwave response associated with two main earthquakes in Tibetan Plateau, China. Adv. Space Res., 62(7), 1675-1689.

Kawanishi, T. et al., 2003. The advanced microwave scanning radiometer for the earth observing system (AMSR-E), NASDA's contribution to the EOS for global energy and water cycle studies.
IEEE Trans. Geosci. Remote Sens., 41(2), 184-194.

Maeda, T. and Takano, T., 2008. Discrimination of local and faint changes from satellite-borne microwave-radiometer data. IEEE Trans. Geosci. Remote Sens., 46(9), 2684-2691.

Maeda, T. and Takano, T., 2010. Detection algorithm of earthquake-related rock failures from satellite-borne microwave radiometer data. IEEE Trans. Geosci. Remote Sens., 48(4), 17681776.

Ma, W. Y., et al., 2018. Influences of multiple layers of air temperature differences on tidal forces and tectonic stress before, during and after the Jiujiang earthquake. Remote Sens. Environ., 210, 159-165.

Mao, W. F., Wu, L. X., and Qi, Y., Impact of Compressive Stress on Microwave Dielectric Properties of Feldspar Specimen. IEEE Trans. Geosci. Remote Sens., 58(2), 1398-1408.

Mao, W. F., et al., 2020. Additional Microwave Radiation from Experimentally Loaded Granite Covered with Sand Layers: Features and Mechanisms. IEEE Trans. Geosci. Remote Sens., to be published.

Miller, H.J., 2004. Tobler's first law and spatial analysis. Ann. Assoc. Am. Geogr., 94, 284-289.

Qiang, Z. J., Xu, X. D., and Dian, C. G., 1997. Case 27 thermal infrared anomaly precursor of impending earthquakes. Pure Appl. Geophys., 149(1). 159-171.

Qi, Y., Wu, L. X., He, M., and Mao, W. F., 2020. SpatioTemporally Weighted Two-Step Method for Retrieving Seismic MBT Anomaly: May 2008 Wenchuan Earthquake Sequence Being a Case. IEEE J. Sel. Topics Appl Earth Observ. Remote Sens., 13, 382-391.

Qin, K., Wu, L. X., Zheng, S., and Liu, S. J., 2013. A deviationtime-space-thermal (DTS-T) method for global earth observation system of systems (GEOSS)-based earthquake anomaly recognition: Criterions and quantify indices. Remote Sens., 5(10), 5143-5151.

Saraf, A. K. and Choudhury, S., 2004. Satellite detects surface thermal anomalies associated with the Algerian earthquakes of May 2003. Int. J. Remote Sens., 26(13), 2705-2713.

Singh, R. P. et al., 2010. Precursory signals using satellite and ground data associated with the Wenchuan earthquake of 12 May 2008. Int. J. Remote Sens., 31(13), 3341-3354.

Takano, T. and Maeda, T., 2009. Experiment and theoretical study of earthquake detection capability by means of microwave passive sensors on a satellite. IEEE Trans. Geosci. Remote Lett., 6(1), 107-111.

Tramutoli, V., Cuomob, V., Filizzola, C., Pergola, N., and Pietrapertosa, C., 2005. Assessing the potential of thermal infrared satellite surveys for monitoring seismically active areas: The case of Kocaeli (Izmit) earthquake. Remote Sens. Environ., 96(3-4), 409-426.

Tronin, A. A., 1996. Satellite thermal survey-A new tool for the study of seismoactive regions. Int. J. Remote Sens., 17(8), 14391455.

Wu, L. X., Qin, K. and Liu, S. J., 2012. GEOSS-based thermal parameters analysis for earthquake anomaly recognition. Proc. IEEE, 100(10), 2891-2907.

Wu, L. X., et.al., 2016. Geosphere coupling and hydrothermal anomalies before the $2009 \mathrm{Mw} 6.3 \mathrm{~L}$ 'Aquila earthquake in Italy. Nat Hazards Earth Syst Sci. 16(8),1859-1880.

Zhao, G. M., Liu, J., Wu, Z. H., 2015. The 2015 Nepal earthquake and the future trend of the Himalayan orogen. Journal of geomechanics, 21(3). 